\title{
EFFECTIVENESS OF DISC EXCISION IN THE TREATMENT OF HERNIATED LUMBAR INTERVERTEBRAL DISC
}

\author{
Maimoona Qadir ${ }^{1}$, Sohail Amir ${ }^{2}$, Muhammad Usman ${ }^{3}$ \\ 1. Khyber Teaching Hospital \\ 2. Naseer Teaching Hospital \\ 3. Naseer Ullah Babar Memorial Hospital
}

\section{ABSTRACT}

\section{OBJECTIVE}

To determine the efficacy of disc excision in the treatment of herniated lumbar intervertebral disc.

\section{METHODOLOGY}

This study was conducted at Neurosurgery Department of Naseer Teaching Hospital, Peshawar from February 2015 to January 2016. The study design was descriptive case series in which consecutive non probability sampling technique was used. Clinical outcome of patients undergoing discectomy was determined using Stauffer-Coventry criteria and patients rated as excellent, good, fair and poor

\section{RESULT}

A total of 88 patients were recruited with $64 \%$ males and $36 \%$ females. Mean age was 39 years +4.68 SD. $70 \%$ patients had $L_{4}-L_{5}$ and $30 \%$ had $L_{5}-S_{1}$ level disc herniation. Laminectomy was performed in $58 \%$, fenestration in $34 \%$ and hemilaminectomy in $8 \%$ patients. Postoperatively at four weeks, satisfactory pain relief reported by $85 \%$ and unsatisfactory pain relief reported by $15 \%$ patients.

\section{CONCLUSION}

Conventional laminactomy, fenestration or hemilaminectomy is a feasible, safe and effective treatment in patients with lumbar disc herniation. Relief of pain is faster for patients assigned to early surgery.

\section{KEY WORDS}

Sciatica, Prolapsed, Intervertebral disc, Disc excision

\section{INTRODUCTION}

Lumbar disc herniation (LDH) is a common complaint among adults with degenerated lumbar intervertebral discs. 1,2,3,4 Patients with lumbar disc disease frequently suffer from continuous back pain, radicular symptoms and weakness. Back pain may be aggravated by position and drive ${ }^{5}$.

\section{Correspondence:}

Dr. Sohail Amir

Naseer Teaching Hospital

Contact: 0321-9181303

Email: dr.sohailamir@gmail.com

https://doi.org/10.37762/jgmds.3-2.38

The underlying mechanism of LDH is disc degeneration or trauma which induces the translocation of nucleus(annulus fibrosis) into the vertebral canal, forcing the nucleus pulposus and compressing spinal cord nerves ${ }^{6}$. The prevalence rates of lower back pain in a number of studies ranged from $12-35 \%{ }^{7}$, with around $10 \%$ patients becoming chronically disabled ${ }^{8}$.Around $20 \%$ of people in their teens have discs with mild signs of degeneration which increases steeply with age so that $10 \%$ of 50 years old discs and $60 \%$ of $70 y e a r s$ old discs are severely degenerated ${ }^{9}$.Disc herniation most commonly occur between $4^{\text {th }}$ and $5^{\text {th }}$ lumbar or $5^{\text {th }}$ lumbar and $1^{\text {st }}$ sacral vertebra ${ }^{10,11,12,13}$. 
Medical treatment includes bed rest, physiotherapy, osteopathic manipulations, massage, anti inflammatory drugs, intravenous sedation and traction therapy ${ }^{14}$.Surgical treatment includes discectomy, fenestration and laminectomy ${ }^{15}$.Success rates for lumbar discectomy ranges between $49-90 \%$. The goal of treatment is to return the patient to normal activities as quickly as possible ${ }^{16}$.After surgical discectomy, $80 \%$ patients reported a decrease of more than two points on visual analogue scale ${ }^{17,18,19}$. The discrete estimation of the effect of symptomatic LDH on the economic system, in terms of days lost to work and reduced productivity is hard to obtain. Although no figures are available in Pakistan, US health care spends over 1 billion dollars annually to redress this disorder. The objective of our study is to determine the efficacy of lumbar disc excision in treatment of herniated intervertebral disc and its impact on relief of back and leg pain and functional improvement.

\section{METHODOLOGY}

This study was conducted prospectively at Department of Neurosurgery Naseer Teaching Hospital Peshawar. The duration of study was from February 2015 to January 2016. Inclusion criteria was patients of either gender, in 15 to 60 years age range and patients whose radicular pain has been confirmed by MRI to be due to intervertebral disc protrusion at $L_{4}-L_{5}$ or $L_{5}-S_{1}$. Patients having caudaacquina syndrome, failed back syndrome, severe stenosis, multilevel disc prolapse, co-morbid diseases and those having obvious spinal deformity were excluded as they made the study biased. All patients fulfilling the inclusion criteria were recruited into the study and admitted through OPD. Approval from hospital ethical committee was obtained. Written informed consent was taken from patients. After admission, detailed history and clinical examination was performed and routine preoperative investigations were sent. All the surgeries were performed by single experienced neurosurgeon having minimum of 7 years of experience. On next operation list, discectomy by either method was performed. All patients operated through posterior approach. An intraoperative cross table lateral radiograph was used to identify the appropriate level. The nerve root was completely decompressed and mobile.

Active measures were taken to prevent infection, deep venous thrombosis and severe pain to get the lungs back to normal function. Patients were observed for 48hours and then discharged to home or rehabilitation facilities. Follow up examination was usually done four weeks postoperatively and response of the patient recorded. All the above mentioned information was entered in a predesigned proforma. Clinical outcome of patients undergoing discectomy was determined using Stauffer-Coventry criteria and patients rated as excellent, good, fair and poor. Patients were considered to have satisfactory outcome if the response was reported to be excellent or good and unsatisfactory if fair or poor. Data was analyzed by SPSS 20.0.Mean and standard deviation was calculated for age and frequencies and percentages for gender, level for disc herniation, type of surgery, pain at 4 week postoperatively (by Stauffer- Coventry criteria). 


\section{RESULTS}

This study comprised of a total of88 cases of LDH. 68(78\%) were in 30-45years age group,13(14\%) fell into age group of $46-60$ years, $7(8 \%)$ of patients fell into age group of $15-30$ years. Mean age was 39 years with standard deviation \pm 4.68 . When gender distribution was analyzed,56(64\%) of cases were males while 32(36\%) were females. Amongst the 88 cases studied, the commonest level of lumbar disc herniation was L4-L5,62(70\%) patients showed LDH at this level whereas 26(30\%) showed at L5-S1 level. Common signs and symptoms and types of surgeries performed are mentioned in tables 1 and 2 . Side of pain among 88 patients was analyzed as $49(56 \%)$ suffered radicular pain on right whereas $39(44 \%)$ presented with radicular pain on left side. Clinical outcome was measured in form of rating of pain as excellent, good, fair and poor by Stauffer -Coventry criteria (table 3 ) at two weeks follow up visit. It was observed that $75(85 \%)$ patients were considered to have a satisfactory outcome while $13(15 \%)$ had an unsatisfactory outcome. Results are narrated in table 4.

Table 1: Common Clinical Presentation of Ldh Patients $(\mathrm{N}=88)$

\begin{tabular}{|l|l|}
\hline Clinical Presentations & Frequency\& Percentage \\
\hline Lower back pain & $88(100 \%)$ \\
\hline Radicular Pain & $88(100 \%)$ \\
\hline Positive SLR & $88(100 \%)$ \\
\hline Numbness & $39(44 \%)$ \\
\hline Paraesthesias & $38(43 \%)$ \\
\hline Limping gate & $18(20 \%)$ \\
\hline Claudication & $13(15 \%)$ \\
\hline Abnormal reflexes & $12(14 \%)$ \\
\hline Motor weakness & $11(13 \%)$ \\
\hline Total & $\mathbf{8 8 ( 1 0 0 \% )}$ \\
\hline
\end{tabular}

Table 2: Stauffer-Coventry Criteria, Determine Clinical Outcome For Patient Undergoing Lumbar Discectomy

\begin{tabular}{|c|c|}
\hline Results & Criteria \\
\hline Excellent & $\begin{array}{l}\text { - Complete relief (>90\%) of pain in the back and lower extremity, returned to } \\
\text { previous activities. }\end{array}$ \\
\hline Good & $\begin{array}{l}\text { - Relief of most of pain( }>70-90 \%) \text { of pain in back and lower extremity. } \\
\text { - Able to return to employment } \\
\text { - } \text { Physical activities not limited } \\
\text { - Analgesics used infrequently }\end{array}$ \\
\hline Fair & $\begin{array}{l}\text { - } \text { Partial relief(>30\%-70\%) of pain in back and lower extremity } \\
\text { - } \quad \text { Able to return to employment with limitations } \\
\text { - } \quad \text { Physical activities definitely limited } \\
\text { - } \quad \text { Mild analgesic used frequently }\end{array}$ \\
\hline Poor & $\begin{array}{l}\text { - } \quad \text { Little or no relief(0-30\%)of pain or worse than preoperatively } \\
\text { - } \quad \text { Disabled for work } \\
\text { - } \quad \text { Physical activities greatly limited } \\
\text { - } \quad \text { Strong analgesics frequently used }\end{array}$ \\
\hline
\end{tabular}


Table 3.Types of Surgeries Performed

\begin{tabular}{|l|l|}
\hline Type of surgery & Frequency \& Percentage \\
\hline Laminectomy & $51(58 \%)$ \\
\hline Fenestration & $30(34 \%)$ \\
\hline Hemilaminectomy & $7(8 \%)$ \\
\hline Total & $\mathbf{8 8 ( 1 0 0 \% )}$ \\
\hline
\end{tabular}

Table 4: Response of Patients Regarding Effectiveness Of Procedure

\begin{tabular}{|l|l|l|}
\hline Response of patient & Frequency \\
\hline Satisfied & Excellent & $55(62 \%)$ \\
\cline { 2 - 3 } & Good & $20(23 \%)$ \\
\hline Not satisfied & Fair & $8(9 \%)$ \\
\cline { 2 - 3 } & Poor & $5(6 \%)$ \\
\hline
\end{tabular}

\section{DISCUSSION}

Lumbar disc herniation is a condition frequently affecting quality of life in young and middle age patients, and most common cause of nerve root pain. The effectiveness of surgery in patients with LDH is without any dispute. ${ }^{20}$ According to a study done in China by Shi $\mathrm{J}$ et al in 2012,sixty patients were recruited out of which $38.3 \%$ were women and $61.7 \%$ were men $^{16}$.Similar results regarding gender were observed in our study. Rehman $\mathrm{R}$ et al in a study conducted at Peshawar enrolled 226 patients, including $63 \%$ males and $36 \%$ females, again showing closer results to ours and a male predominence. ${ }^{26}$ Shah et al in a study done concluded that incidence of LDH is more in age range of 31-40 years, followed by age group of 41-50 years, amongst the total of 62 patients studied $^{21}$.Our study is also showing close results with commonest age group being 31-45 years, followed by age group of 46-60 years.

Ahmad et al in a study conducted in 2010 depicted the L4-L5 level to be the commonest spinal level effected in $62 \%$ patients, followed by L5-S1 effecting $32 \%$ patients. ${ }^{22}$ Similar results were seen in our study. Shah et al in their study applied the procedure of laminectomy in $60 \%$,fenestration in $29 \%$ and hemilaminectomy in $11 \%$ patients ${ }^{21}$.In our study, choice of surgical procedure was in same order as laminectomy was performed in $51(58 \%)$,fenestration in $30(34 \%)$ and hemilaminectomy in $7(8 \%)$ patients. On the basis of data from three different studies, it was concluded that surgical discectomy provides effective clinical relief for carefully selected patients with sciatica as a result of LDH that could not be resolved with conservative management. ${ }^{23,24}$

Connell JEA et al analyzed the severity of pain in his study, concluding that postoperatively in patients with disc excision, $82 \%$ patients didn't had any pain whereas $14 \%$ had mild pain. ${ }^{24}$ Similarly we observed $85 \%$ of our patients becoming pain free after disc excision surgery. Similarly satisfaction rates of $86.7 \%$ were observed in a Turkish study done by Hai. NIE et al in $2010 .{ }^{25}$ There are several limitations in this study. All the procedures were performed by a single spine centre and the results therefore need to be confirmed in a multicentre study. In addition the 
follow up period was very short i.e., four weeks, and the long term outcome of surgical management in patients with LDH cannot be ensured.

\section{CONCLUSION}

Disc excision in form of laminectomy, fenestration or hemilaminectomy is a feasible and effective option for patients presenting with LDH. In comparison to conservative management, the surgical techniques provide immediate and long lasting relief, but careful attention to patient selection, surgical indication and perioperative management is mandatory.

\section{REFERENCES}

1. Haddadi K. Paediatric lumbar disc herniation:A review of manifestations, diagnosis and management. J Paediatr Rev 2016; 4(1): e4725.

2. Schoenfeld AJ, Weiner BK. Treatment of lumbar disc herniation; Evidence based practice. Int J Gen Med 2010; 3: 209-13.

3. Bono CM, Wineski R, Garfin SR. Lumbar disc herniations. The Spine. $5^{\text {th }}$ ed. Philadelphia, PA: Saundesr; 2006.

4. McCulloch JA, Edwards CC, Riew KD. Lumbar microdiscectomy. Master techniques in Orthopaedic surgery: The Spine. Philadelphia, PA: Lippincott Williams \& Wilkins; 2002.

5. Garcia J, delValee ME, Calavia MG, Garcia-Suarez O,Lopex-Muniz A, Otero J. Intervertebral disc, sensory nerves and neurotrophins: who is who is discogenic pain? J Anat 2010; 217(1): 1-15.

6. Postaccini F. Management of herniation of the lumbar disc. J Bone Joint Surgery 1999; 81(4): $567-$ 75.

7. Maniadakis N, Gray A. The economic burden of back pain in the UK. Pain 2000; 84:95-103.

8. Raj PP.Intervertebral disc: Anatomy-Physiology-Pathophysiology-Tretment. World institute of pain 2008; 8(1) 18-44.

9. Miller J,Schmatz C, Schultz A. Lumbar disc degeneration. Correlation with age,sex and spine level in 6000 autopsy specimens. Spine 1988; 13:173-78.

10. Stafford MA, Peng P, Hill DA. Schiatica: A review of history, epidemiology, pathogenesis, and the role of epidural steroid injection in management. Br J Anaesth 2007; 99: 86-9.

11. Sangwan SS, Kundu ZS, Singh R, Kamboj $P$, Siwach RC, Aggarwal P. Lumbar disc excision through fenestration. Spine 2006; 40: 86-9.

12. Millette PC. Classification, diagnostic imaging and imaging catheterization of a lumbar herniated disc. RadiolClin North Am 2000; 38: 1267-91. 
13. Ong A, Anderson J, Roche J. A pilot study of the prevalene of lumbar disc degeneration in elite athletes with lower bak pain at the Sydney 2000 Olympic Games. Br J Sports Med 2003; 37: 263-66.

14. Skovrlj B, Gilligan J, Cuttler HS, Qureshi SA. Minimally invasive procedures on the lumbar spine. World J Clin Cases 2015; 16: 3(1):1-9.

15. Ongeti KW, Ogeng JA, Bundi PK, GakkuLN.Treatmentandoutcome of herniated lumbar intervertebral disc in a referral hospital in Kenya. East AfrOrth J 2009; 3: 52-6.

16. Shi J, Wang $Y$, Zhou $F$, Zhang $H$, Yang $H$. Long term clinical outcomes in patients undergoing lumbar discectomy by fenestration. J Int Med Res 2012; 40: 2355-61.

17. Manchikanti L, Derby R, Benyamin RM, Helm S.A systematic review of mechanical lumbar disc decompression with nucleoplasty. Pain Physician 2009; 12(3): 561-72.

18. Stafford MA, Peng P, Hill DA. Schiatica: a review of history, epidemiology, pathogenesis and the role of epidural steroid injection in management. Br J Anaesth 2007; 99(4): 461-73.

19. Ahmad M, Arrotegui JI, Bjornsson A. Clinical factors predicting outcome after surgery for herniated lumbar discs: an epidemiological multivariate analysis. J Spinal Disorders 2003; 3: 205-9.

20. Jaobs WCH, Tulder M, Arts M, Rubinstein SM. Surgery versus conservative management of schiatica due to lumbar herniated disc: a systematic review. Eur Spine J 2011; 20: 513-22.

21. Shah M, Khan MM, Safi T, Aman A, Ahmad A, Shah MA, Ahmad F. Effectiveness of disc excision in the treatment of herniated lumbar intervertebral disc. J Med Sci 2015; 23(3): 153-7.

22. Ahmad N, Mahmood A, Ahmad I, Shafi K, Aziz A. Immediate relief of lumbar radicular pain after surgical excision of prolapsed intervertebral disc. JPOA 2010; 22(1): 1-6.

23. Gibson JN, Waddell G. Surgical interventions for lumbar disc prolapsed. Cochrane database of systematic reviews 2007; 2:12-56.

24. O'Connell JEA. Protrusions of the lumbar intervertebral discs. J Bone Joint Surg 2003; 33: 8-30.

25. Hai NIE, Dianming J, YunshengOu. Efficacy and safety of surgery for lumbar disc herniation in patients aged 80 and older. Turkish Neurosurg 2011; 21(2): 172-6.

26. Rehman R, Ayoob S, Rizwan R, Shah M. The effectiveness of surgery for the symptomatic prolapsed lumbar intervertebral disc. Pak J Neurol Surgery 2014; 18(1): 87-90.

LICENSE: JGMDS publishes its articles under a Creative Commons Attribution Non-Commercial Share-Alike license (CC-BY-NC-SA 4.0). COPYRIGHTS: Authors retain the rights without any restrictions to freely download, print, share and disseminate the article for any lawful purpose. It includes scholarly networks such as Research Gate, Google Scholar, LinkedIn, Academia.edu, Twitter, and other academic or professional networking sites. 